\title{
Biomechanical comparison using finite element analysis of different screw configurations in the fixation of femoral neck fractures
}

\author{
K. Gok ${ }^{1}$ and S. Inal ${ }^{2}$ \\ ${ }^{1}$ Dumlupinar University, Kütahya Vocational School of Technical Sciences, Germiyan Campus, \\ 43110 Kütahya, Turkey \\ ${ }^{2}$ Dumlupinar University, School of Medicine, Department of Orthopaedic Surgery, Campus of Evliya Celebi, \\ 43100 Kütahya, Turkey \\ Correspondence to: K. Gok (kadirgok67@hotmail.com)
}

Received: 11 May 2015 - Revised: 9 July 2015 - Accepted: 14 August 2015 - Published: 9 September 2015

\begin{abstract}
In this research, biomechanical behaviors of five different configurations of screws used for stabilization of femoral neck fracture under axial loading have been examined, and which configuration is best has been investigated. A point cloud was obtained after scanning the human femoral model with a three dimensional (3-D) scanner, and this point cloud was converted to a 3-D femoral model by Geomagic Studio software. Femoral neck fracture was modeled by SolidWorks software for five different configurations: dual parallel, triple parallel, triangle, inverted triangle and square, and computer-aided numerical analysis of different configurations were carried out by ANSYS Workbench finite element analysis (FEA) software. For each configuration, mesh process, loading status (axial), boundary conditions and material model were applied in finite element analysis software. Von Mises stress values in the upper and lower proximity of the femur and screws were calculated. According to FEA results, it was particularly advantageous to use the fixation type of triangle configuration. The lowest values are found as $223.32 \mathrm{MPa}$ at the lower, $63.34 \mathrm{MPa}$ at the upper proximity and $493.24 \mathrm{MPa}$ at the screws in triangle configuration. This showed that this configuration creates minimum stress at the upper and lower proximity of the fracture line. Clinically, we believe that the lowest stress values which are created by triangle configuration encompass the most advantageous method. In clinical practices, it is believed that using more than three screws does not provide any benefit. Furthermore, the highest stresses are as follows: at upper proximity $394.79 \mathrm{MPa}$ in triple parallel configuration, for lower proximity $651.2 \mathrm{MPa}$ in square configuration and for screw $2459 \mathrm{MPa}$ in inverted triangle.
\end{abstract}

1

\section{Introduction}

In our daily life, people can be faced with undesired traumas. As a result of these traumas, femoral neck fractures may occur in the skeletal system. Femoral neck fractures are serious traumas that can lead to pneumonia, pulmonary embolism or death. Therefore, fixing the accuracy and stability of these fractures is necessary. The different configurations of screw fixation are used for stabilization of femoral neck fractures. The question of the best fixation type in surgical treatment of femoral neck fractures is still subject of debate today (Basso et al., 2012; Deneka et al., 1997; Filipov, 2011; Martens et al., 1979; Zdero et al., 2010). In general, although screw fixations of these fractures have been described as appropriate, there are only few studies that contain evidence based on biomechanics regarding which configuration or how many screws result in better stabilization (Audekercke et al., 1979; Cody et al., 2000; Martens et al., 1979; Springer et al., 1991; Swiontkowski et al., 1987). In clinical practice, morbidity related to the fixation of a femoral neck fracture might be due to the configuration of screws that is used; a superior fixation absolutely will create less morbidity (PJ, 1996). Today, biomechanical analyses are performed by using finite element analysis (FEA) in many areas of medicine. In this study, 


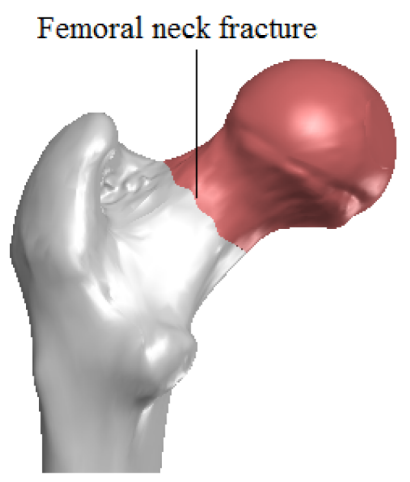

Figure 1. Femoral neck fracture.

we aimed to research what the best stable fixation practice might be by applying five different screw configuration types on the femoral neck fracture model with FEA method.

\section{Computer-aided design (CAD) and finite element analysis}

The human femoral model used in this study was scanned using a 3-D scanner and point cloud was obtained. This process is called reverse engineering (RE). RE process is used to copy the complex shapes and designs by special software and hardware. This method decreases the design process of a product. In particular, it is very important when CAD models of products have been lost. However, in traditional production sequence, reverse engineering typically starts with measuring an existing object so that a solid model can be deduced in order to make use of the advantages of CAD/CAM/CAE technologies (Várady et al., 1997). Later, 3-D model of femur was created using point cloud data by Geomagic Studio 10 program. The scanned data were taken as point cloud data in STL format and converted to Parasolid format using the Rapidform program. The Parasolid format was opened in SolidWorks program and a femoral neck fracture on the 3-D femur model was created as shown in Fig. 1. In order to stabilize the femur neck fracture, $M=6.5$ screws (cancellous bone screw $6.5 \mathrm{~mm}$ diameter and $16 \mathrm{~mm}$ thread) were used in this study. Screws were scanned (Fig. 2) using 3-D scanner and modeled in SolidWorks program. Finally, five different configurations - dual parallel, triple parallel, triangle, inverted triangle and square (Fig. 3) - were created using this femur neck fracture model as shown in Fig. 4.

Computer-aided numerical analysis to stabilize the five configurations after fixation was performed using ANSYS Workbench software. The 3-D CAD models of the five configurations (Figs. 3 and 4) were imported into the ANSYS Workbench software to prepare the FEA. Load, boundary conditions and material models were defined in ANSYS Workbench.

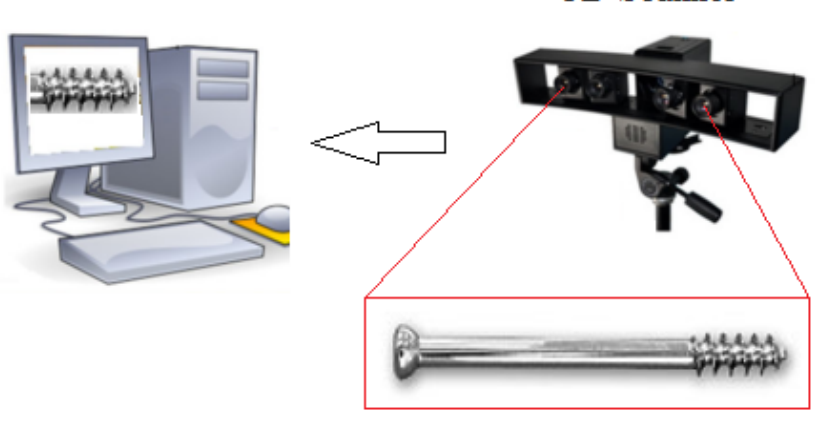

Figure 2. The scanning of screw using a 3-D scanner.

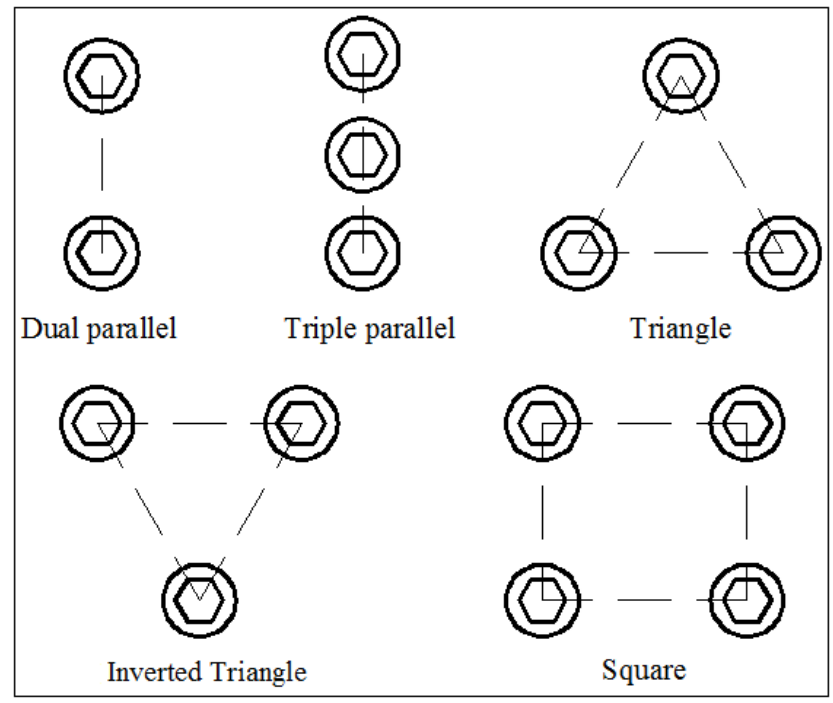

Figure 3. Schematic view of five different configurations for femoral neck fracture.

\section{Loading and boundary conditions}

The mesh process was performed using hex dominant finite element for the FEA modeling after importing five different configurations of 3-D models into the ANSYS Workbench software. The FEA model has 92552 nodes and 33117 elements. While the mesh density for the femur was inputted as $4 \mathrm{~mm}$, each screw was inputted as $1 \mathrm{~mm}$, as shown in Fig. $5 \mathrm{a}$. A load of 350 newton $(\mathrm{N})$ in axial direction was applied to the femoral head, and it was fixed from the distal condylar articular face, as shown in Fig. 5b. Contact types the between bone-bone interaction and screw-bone interaction were defined as a frictional contact. Friction coefficients were taken as 0.46 for bone-bone interactions and 0.42 for screw-bone interaction (Goffin et al., 2013). Finally, convergence analysis was conducted as shown in Fig. 6. The force convergence was commonly used in non-linear analyses. If solution is not convergence, there are one or more problems. The purple line on the convergence graph should be acted on the cyan line in order to obtain a good solution. This status depends on 


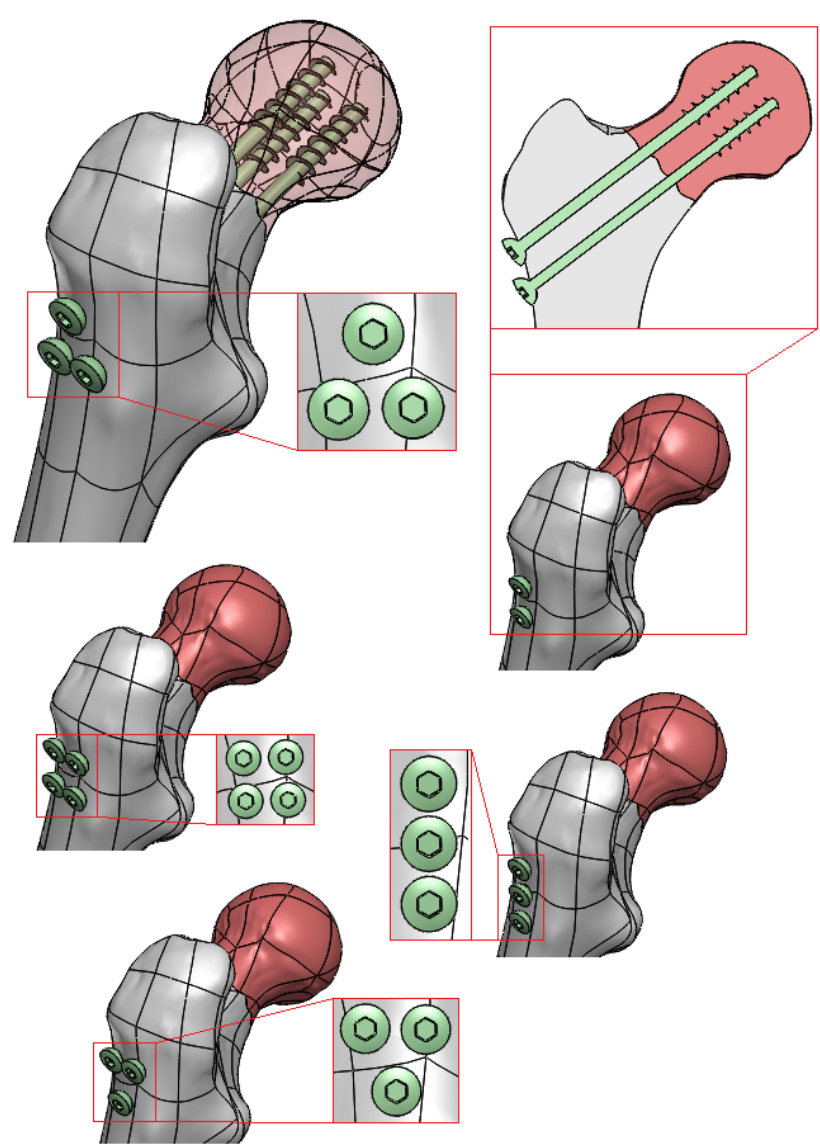

Figure 4. 3-D view of five different configurations for femoral neck fracture.

Table 1. Mechanical properties of bone and screw used in the FEA (Yuan-Kun et al., 2009).

\begin{tabular}{lrr}
\hline Parameters & $\begin{array}{r}\text { Screw (ANSYS Workbench } \\
\text { Material Library) }\end{array}$ & $\begin{array}{r}\text { Bone (Yuan-Kun } \\
\text { et al., 2009) }\end{array}$ \\
\hline Density $\left(\mathrm{kg} \mathrm{m}^{-3}\right.$ ) & 4620 & 2100 \\
Young's modulus (MPa) & 96000 & 17000 \\
Yield strength (MPa) & 930 & 135 \\
Ultimate strength (MPa) & 1070 & 148 \\
Poisson's ratio & 0.36 & 0.35 \\
\hline
\end{tabular}

boundary conditions such as friction, contact type and others.

Mechanical properties of bone and screw used in the FEA analyses are given in Table 1. Titanium material was selected for screws, and its mechanical properties were taken from ANSYS Workbench Material Library. Linear isotropic material model was used for mechanical behaviors of bone and screws. The human femur was taken into account as cortical. Müller et al. (1991) mentioned that the anisotropy of bone, i.e., its different mechanical properties along different axes, does not play a major role in internal fixation and will therefore be neglected here.

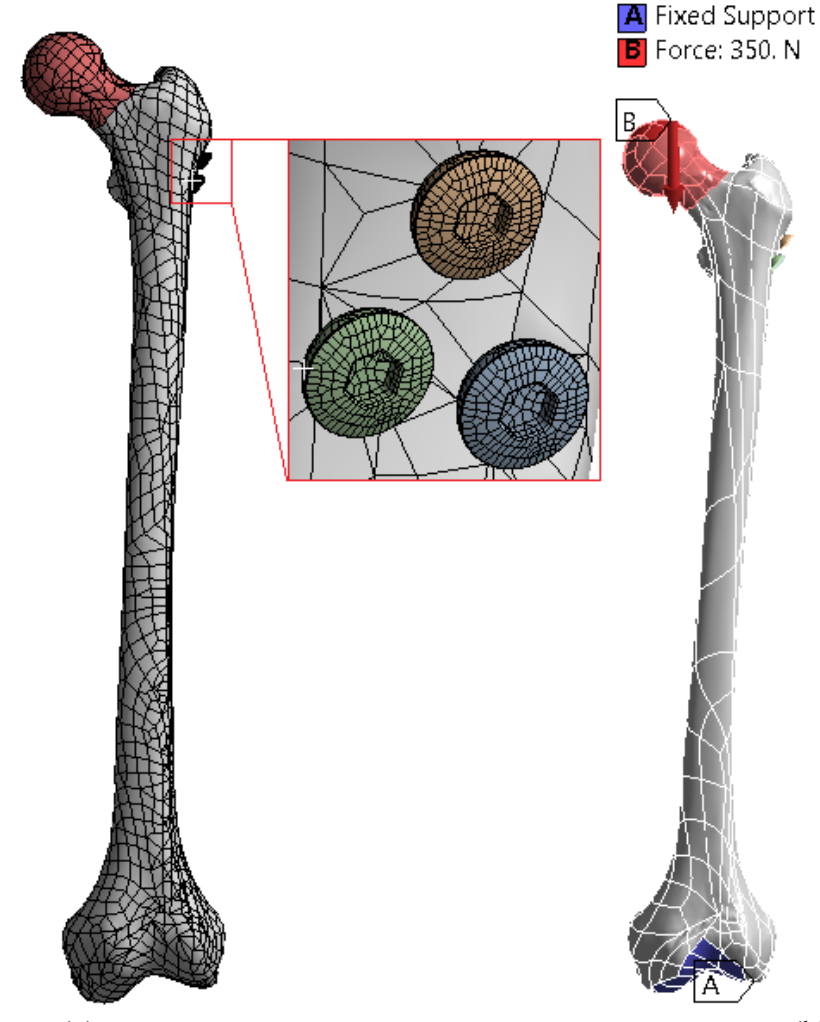

(a)

(b)

Figure 5. Mesh structure of triangle configuration (a), loading and fixing (b).

\section{Results}

After inputting loading and boundary conditions, FEA analysis was solved. According to FEA results, maximum stress values on upper and lower proximity of femoral bone and screws are given in Table 2. These stress values have been evaluated according to the von Mises criteria. According to this criterion, the von Mises stress is an equivalent or effective stress at which yielding is predicted to occur in ductile materials. If the equivalent stress exceeds the yield stress of the material, yielding occurs at that point. In most literature, such a stress is derived using principal axes in terms of the principal stresses (Fig. 7) as in Eq. (1). In latest editions, the von Mises stress with respect to multi-axes stresses (Fig. 8) can also be expressed as in Eq. (2) (Jong and Springer, 2009).

$\sigma_{\mathrm{Equ}}=\frac{1}{\sqrt{2}}\left[\left(\sigma_{1}-\sigma_{2}\right)^{2}+\left(\sigma_{2}-\sigma_{3}\right)^{2}+\left(\sigma_{3}-\sigma_{1}\right)^{2}\right]^{\frac{1}{2}}$ 


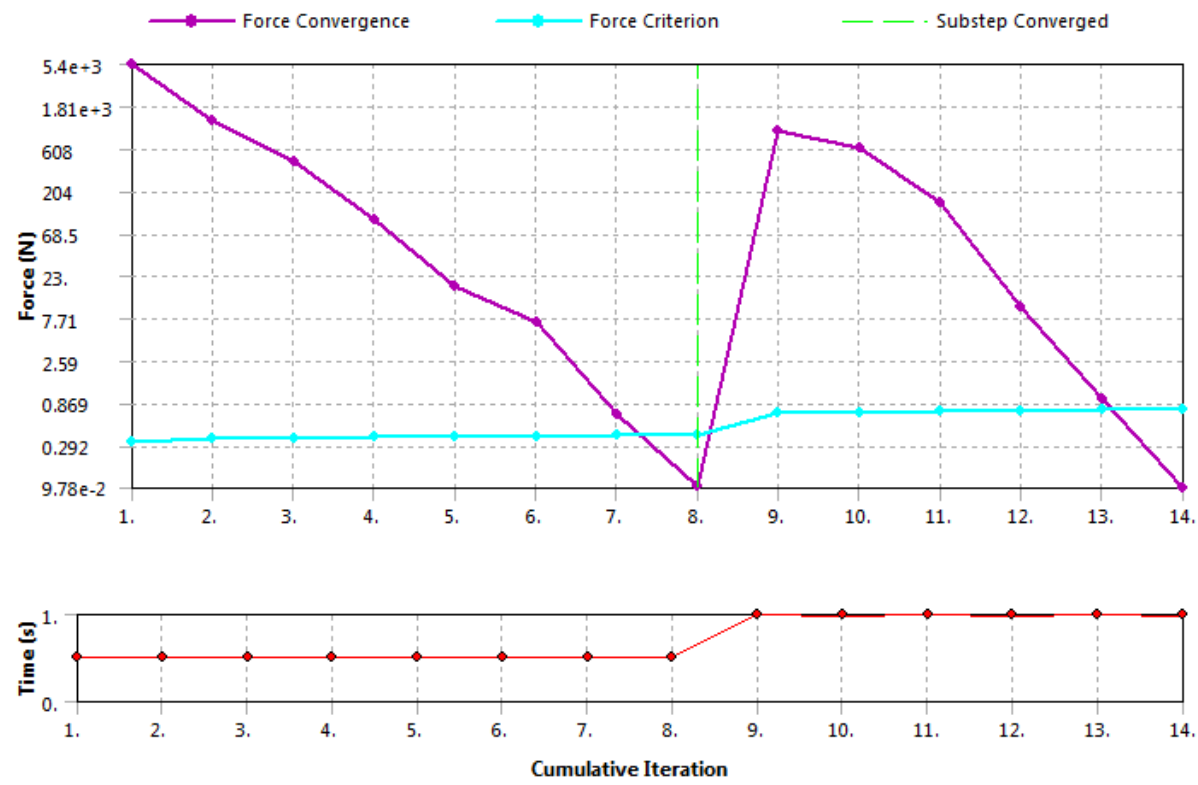

Figure 6. Convergence analysis.

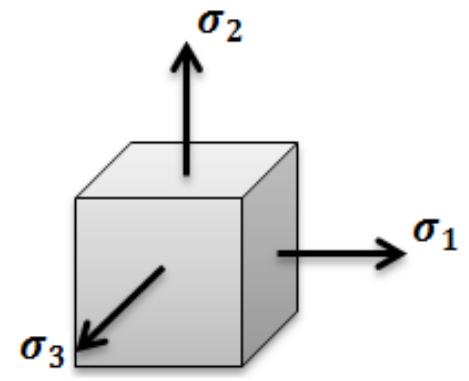

Figure 7. The principal stresses.

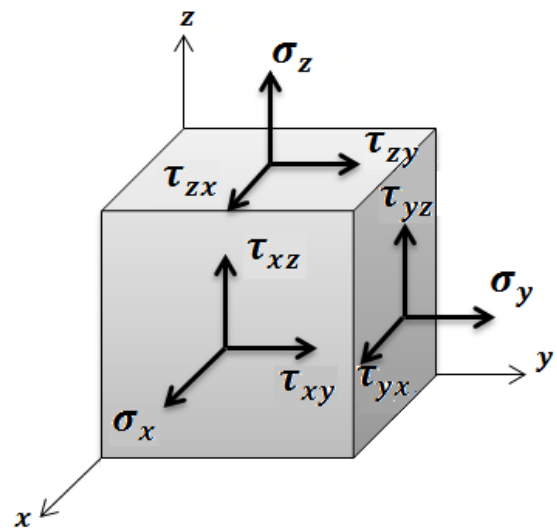

Figure 8. The multi-axial stress state.

$$
\begin{aligned}
& \sigma_{\mathrm{Equ}}=\frac{1}{\sqrt{2}}\left[\left(\sigma_{x}-\sigma_{y}\right)^{2}+\left(\sigma_{y}-\sigma_{z}\right)^{2}+\left(\sigma_{z}-\sigma_{x}\right)^{2}\right. \\
& \left.+6\left(\tau_{x y}^{2}+\tau_{y z}^{2}+\tau_{z x}^{2}\right)\right]^{\frac{1}{2}}
\end{aligned}
$$

Table 2. The stress values in bone and screws.

\begin{tabular}{llrrr}
\hline \multirow{2}{*}{ No. Fixation type } & \multicolumn{3}{c}{ Stress distributions } \\
\cline { 3 - 5 } & & $\begin{array}{r}\text { Screw } \\
(\mathrm{MPa})\end{array}$ & $\begin{array}{r}\text { Upper proximity } \\
(\mathrm{MPa})\end{array}$ & $\begin{array}{r}\text { Lower proximity } \\
(\mathrm{MPa})\end{array}$ \\
\hline 1 & Dual parallel & 2157.2 & 369.49 & 521.28 \\
2 & Triple parallel & 1448 & 394.79 & 599.88 \\
3 & Triangle & 493.24 & 63.34 & 223.32 \\
4 & Inverted triangle & 2459 & 355.32 & 427.75 \\
5 & Square & 2121.2 & 371.75 & 651.2 \\
\hline
\end{tabular}

As shown in Table 2, it is remarkable under axial loading. The lowest stress values occurring in bone and screws have occurred in triangle configuration and results are as follows: for upper proximity of femur $63.34 \mathrm{MPa}$, for lower proximity the femur is $223.32 \mathrm{MPa}$, and for screws $493.24 \mathrm{MPa}$. The highest values have occurred as follows: for upper proximity of femur is $394.79 \mathrm{MPa}$ with triple parallel configuration, for lower proximity of femur $651.2 \mathrm{MPa}$ with square configuration, and for screws $2459 \mathrm{MPa}$ with inverted triangle configuration. Figure 9 shows the values of stress of axial loading on upper proximity of bone with different configurations, and Fig. 10 shows values for lower proximity bone. Lastly, stress distributions occurring in the screws are shown in Fig. 11.

\section{Discussion}

Comparison of different configurations of the screws used for stabilization of femoral neck fracture has been studied in biomechanics (Baitner et al., 1999; Holmes et al., 1993; Husby et al., 1987, 1989; Selvan et al., 2004). Reviewing the literature, it is reported in studies that the ideal configuration 

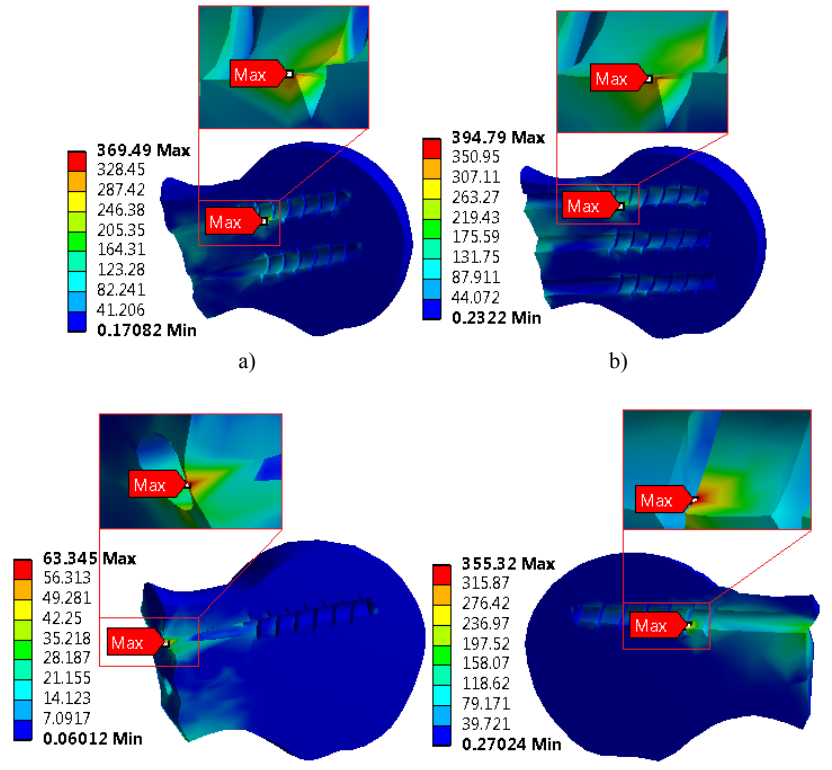

c)

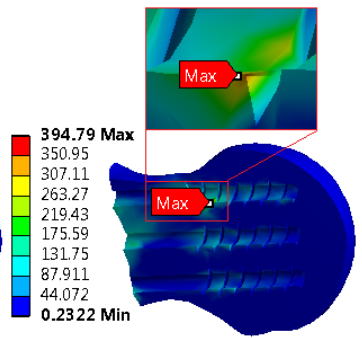

b)

d)

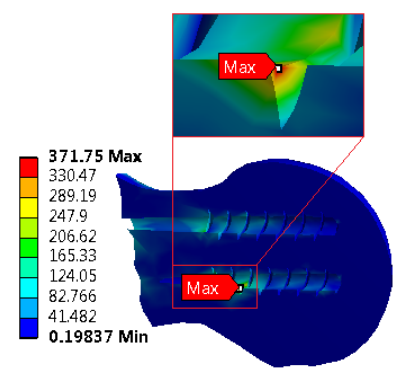

e)

Figure 9. Stress distribution occurring at the upper proximity of femoral bone under axial loading: (a) dual parallel, (b) triple parallel, (c) triangle, (d) inverted triangle, and (e) square.

of screws is two screws for proximal and one for distal in inverted triangle configuration (Kyle, 2009; Ly and Swiontkowski, 2009; Melvin and Happenstall, 2009; Schmidt et al., 2005). On the contrary, in another study, it is reported that triangle configuration is superior to other configurations (Selvan et al., 2004). It has also been stated that using three or four screws provides similar stability in the femoral head (Kyle, 2009; Lavelle, 2003; Ly and Swiontkowski, 2009; Schmidt et al., 2005; Swiontkowski, 2003). In a review article published by $\mathrm{Wu}$ (2010), it is mentioned that inverted triangle configuration is biomechanically superior to traditional triangle configuration. He justifies the superiority of the inverted triangle configuration by explaining the advantage of longer lever arms of two upper screws because during daily activity the loads on the femoral head alternate anteriorly and posteriorly. In our research, we have compared five different configurations: dual parallel, triple parallel, triangle, inverted triangle and square. The stress values show that the triangle configuration during the axial loading has bet-

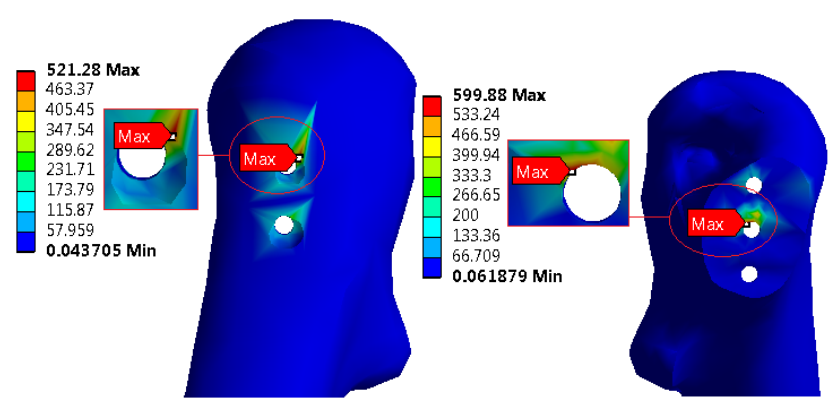

a)

b)

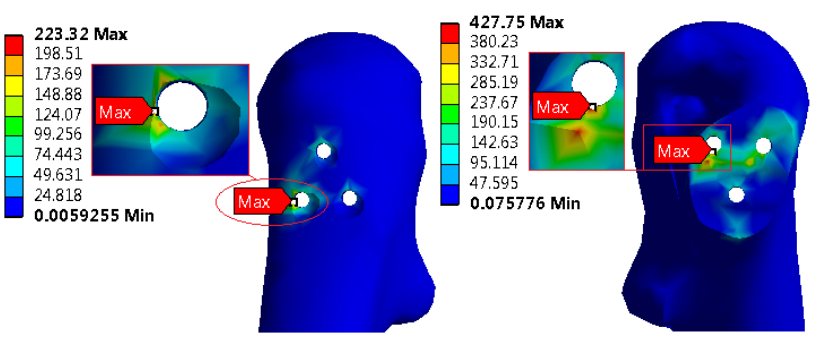

c)

d)

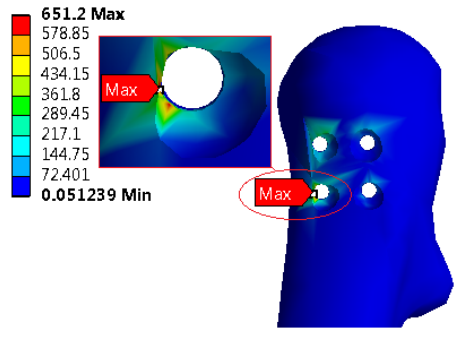

e)

Figure 10. Stress distribution occurring at the lower proximity of femoral bone under axial loading: (a) dual parallel, (b) triple parallel, (c) triangle, (d) inverted triangle, and (e) square.

ter stabilization, since the distribution of loads occurs firstly on the upper screw and then transfers to lower two screws in a controlled manner in triangle configuration. This situation can be explained biomechanically by pyramid structure. It is thought that as long as the forces are transferred down in a controlled manner in the pyramid, the material is not deformed. One of the most important points is the type of triangle - whether it is an isosceles or equilateral. The stress values with this kind of configurations are equally distributed through the system. Parallel to this situation, triangle configuration created minimum stress values in our study. In clinical practice, low stress means safe fracture line and fixation technique. Stress values have been found high on fracture line and screws in dual parallel, triple parallel, inverted triangle and square configurations. We think that the reason for this situation is asymmetrical and unbalanced distribution of the stress. We believe that triangle configuration is superior in the stabilization of femoral neck fractures, and the biomechanical evidence of this case can be explained with pyramid 


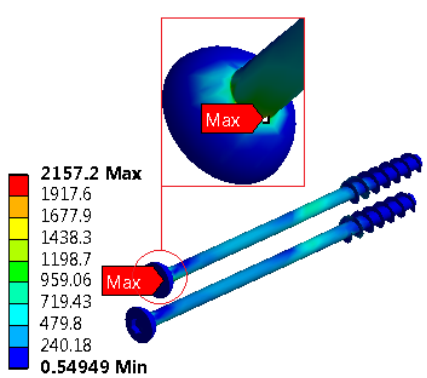

a)

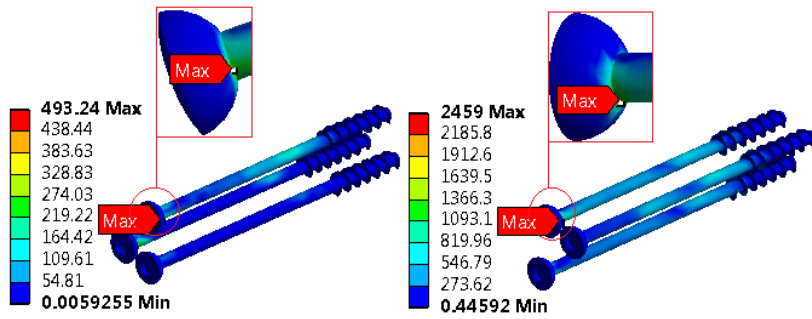

c)

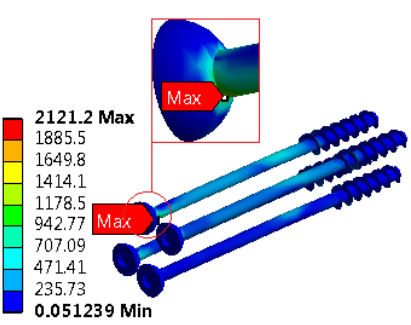

e)

Figure 11. Stress distribution occurring in the screws under axial loading: (a) dual parallel, (b) triple parallel, (c) triangle, (d) inverted triangle, and (e) square.

theory. In our opinion, using more than three screws would be harmful for stabilization in clinical practices.

\section{Conclusions}

In this research, biomechanical behaviors of five different screw configurations (dual parallel, triple parallel, triangle, inverted triangle and square) that are applied for the stabilization of femoral neck fracture are investigated. The stress values on the upper and lower proximity of the femur and screws under axial loading have been analyzed, and which configuration is more advantageous has been researched. According to FEA results, it has been found that fixation in triangle configuration is more advantageous. Additionally, in clinical practice, it is thought that the use of more than three screws for stabilization will not be beneficial. We think that further biomechanical studies are needed to improve the safety of stabilization of femoral neck fractures treated with different screw configurations.
Edited by: P. Flores

Reviewed by: three anonymous referees

\section{References}

Audekercke, R. V., Martens, M., Mulier, J. C., and Stuyck, J.: Experimental Study on Internal Fixation of Femoral Neck Fractures, Clin. Orthop. Relat. Res., 141, 203-212, 1979.

Baitner, A. C., Maurer, S. G., Hickey, D. G., Jazrawi, L. M., Kummer, F. J., Jamal, J., Goldman, S., and Koval, K. J.: Vertical Shear Fractures of the Femoral Neck A Biomechanical Study, Clin. Orthop. Relat. Res., 367, 300-305, 1999.

Basso, T., Klaksvik, J., Syversen, U., and Foss, O. A.: Biomechanical femoral neck fracture experiments - A narrative review, Injury, 43, 1633-1639, 2012.

Cody, D. D., Hou, F. J., Divine, G. W., and Fyhrie, D. P.: Femoral structure and stiffness in patients with femoral neck fracture, J. Orthop. Res., 18, 443-448, 2000.

Deneka, D. A., Simonian, P. T., Stankewich, C. J., Eckert, D., Chapman, J. R., and Tencer, A. F.: Biomechanical Comparison of Internal Fixation Techniques for the Treatment of Unstable Basicervical Femoral Neck Fractures, J. Orthop. Trauma, 11, 337 343, 1997.

Filipov, O.: Biplane double-supported screw fixation (F-technique): a method of screw fixation at osteoporotic fractures of the femoral neck, Eur. J. Orthop. Surg. Traumatol., 21, 539-543, 2011.

Goffin, J. M., Pankaj, P., and Simpson, A. H.: The importance of lag screw position for the stabilization of trochanteric fractures with a sliding hip screw: A subject-specific finite element study, J. Orthop. Res., 31, 596-600, 2013.

Holmes, C. A., Edwards, W. T., Myers, E. R., Lewallen, D. G., White, A. A. I., and Hayes, W. C.: Biomechanics of Pin and Screw Fixation of Femoral Neck Fractures, J. Orthop. Trauma, 7, 242-247, 1993.

Husby, T., Alho, A., Hoiseth, A., and Fonstelien, E.: Strength of femoral neck fracture fixation: Comparison of six techniques in cadavers, Acta Orthop., 58, 634-637, 1987.

Husby, T., Alho, A., and Rønningen, H.: Stability of femoral neck osteosynthesis: Comparison of fixation methods in cadavers, Acta Orthop., 60, 299-302, 1989.

Jong, I.-C. and Springer, W.: Teaching von Mises Stress: From Principal Axes To Non-Principal Axes, American Society for Engineering Education, 2009.

Kregor, P. J.: The effect of femoral neck fractures on femoral head blood flow, Orthopedics, 19, 1031-1036, 1996.

Kyle, R. F.: Fractures of the femoral neck, in: Instructional Course Lectures, edited by: Azar, F. M. and O'Connor, M. I., 58. c., American Academy of Orthopaedic Surgeons, USA, 2009.

Lavelle, D. G.: Fractures of hip, in: Campbell's Operative Orthopaedics, edited by: Canale, S. T., Mosby-Year Book, St. Louis, 2003.

Ly, T. V. and Swiontkowski, M. F.: Treatment of femoral neck fractures in young adults, in: Instructional Course Lectures, edited by: Azar, F. M. and O'Connor, M. I., 58. c., American Academy of Orthopaedic Surgeons, USA, 2009.

Martens, M., Audekercke, R. V., Mulier, J. C., and Stuyck, J.: Clinical Study on Internal Fixation of Femoral Neck Fractures, Clin. Orthop. Relat. Res., 141, 199-202, 1979. 
Material Library of ANSYS Workbench 14.5 Simulation Software, 2015.

Melvin, J. S. and Happenstall, R. B.: Hip fractures, in: Gowned and Gloved Orthopaedics: Introduction to Common Procedures, edited by: Sheth, N. P. and Lonner, J. H., Saunders Co., Philadelphia, 2009.

Müller, M. E., Perren, S. M., Allgöwer, M., and Osteosynthesefragen, A. f.: Manual of Internal Fixation: Techniques Recommended by the AO-ASIF Group, Springer-Verlag, 1991.

Schmidt, A. H., Asnis, S. E., Haidukewych, Gi, Koval, K. J., and Thorngren, K. G.: Femoral neck fractures, in: Instructional Course Lectures, edited by: Pellegrini, V. D., American Academy of Orthopaedic Surgeons, USA, 2005.

Selvan, V. T., Oakley, M. J., Rangan, A., and Al-Lami, M. K.: Optimum configuration of cannulated hip screws for the fixation of intracapsular hip fractures: a biomechanical study, Injury, 35, 136-141, 2004.

Springer, E. R., Lachiewicz, P. F., and Gilbert, J. A.: Internal Fixation of Femoral Neck Fractures: A Comparative Biomechanical Study of Knowles Pins and 6.5-mm Cancellous Screws, Clin. Orthop. Relat. Res., 267, 85-92, 1991.

Swiontkowski, M. F.: Intracapsular hip fractures, in: Skeletal Trauma, edited by: Browner, B. D., Jupiter, J. B., Levine, A. M., and Trafton, P. G., Saunders Co., Philadelphia, 2003.
Swiontkowski, M. F., Harrington, R. M., Keller, T. S., and Van Patten, P. K.: Torsion and bending analysis of internal fixation techniques for femoral neck fractures: The role of implant design and bone density, J. Orthop. Res., 5, 433-444, 1987.

Várady, T., Martin, R. R., and Cox, J.: Reverse engineering of geometric models - an introduction, Comput. Aided Design, 29, 255-268, 1997.

Wu, C. C.: Using Biomechanics to Improve the Surgical Technique for Internal Fixation of Intracapsular Femoral Neck Fractures, Chang Gung Med. J., 33, 241-251, 2010.

Yuan-Kun, T., Yau-Chia, L., Wen-Jen, Y., Li-Wen, C., You-Yao, H., Yung-Chuan, C., and Li-Chiang, L.: Temperature Rise Simulation During a Kirschner Pin Drilling in Bone, Beijing, 1-4, 1113 June 2009.

Zdero, R., Keast-Butler, O., and Schemitsch, E. H.: A Biomechanical Comparison of Two Triple-Screw Methods for Femoral Neck Fracture Fixation in a Synthetic Bone Model, J. Trauma Acute Care. Surg., 69, 1537-1544, 1510.1097/TA.1530b1013e3181efb1531d1531, 2010. 